\title{
Clinical Significance of Pulmonary Arteriovenous Malformation Reperfusion
}

\author{
Claire Kaufman ${ }^{1}$ Katharine Henderson ${ }^{2}$ Jeffrey Pollak ${ }^{2}$ \\ ${ }^{1}$ Department of Radiology, University of California San Diego School \\ of Medicine, San Diego, California, United States \\ ${ }^{2}$ Department Radiology and Biomedical Imaging and the Yale HHT \\ Center, Yale University School of Medicine, New Haven, Connecticut,

\begin{abstract}
Address for correspondence Claire Kaufman, MD, Department of Radiology, University of California San Diego School of Medicine, San Diego, CA 92093, United States
\end{abstract} \\ (e-mail: Claire.Kaufman@gmail.com).
} United States

J Clin Interv Radiol ISVIR 2017;1:156-160.

\begin{abstract}
Keywords

- pulmonary arteriovenous malformation

- embolization

- hereditary hemorrhagic telangiectasia

The purpose of this study was to assess the clinical significance of reperfused pulmonary arteriovenous malformations (rPAVM) after embolization. This study is a retrospective review of all patients from a single HHT center who underwent pulmonary arteriovenous malformation (PAVM) embolization between January 1 , 2006 and December 30, 2007. Clinical history, imaging findings (including reperfusion), and symptoms seen in the setting of PAVMs were reviewed both at the time of embolization and during the subsequent follow-up through December 30, 2013. During the 2-year treatment period, 101 patients underwent PAVM embolization. During the initial embolization, 27 patients were found to have reperfusion of a previously embolized PAVM. During the follow-up period, none of these patients had recurrence of the rPAVM. Three patients who underwent an embolization procedure for the first time at the initial procedure were subsequently found to have rPAVM during the follow-up period. This resulted in a total of 30 patients with rPAVMs. Eighteen (60\%) of the 30 patients were found to be symptomatic at the time of presentation with rPAVM. However, 14 had at least one other significant PAVM at the time of diagnosis of reperfusion. Only two symptomatic patients had only rPAVM, both with mild manifestations. Two patients were excluded from the study as their symptoms were attributed to other medical comorbidities. The majority of symptomatic patients with rPAVM had additional PAVMs that required embolization. Neither of the symptomatic patients with an isolated rPAVM had severe manifestations.
\end{abstract}

\section{Introduction}

Pulmonary arteriovenous malformations (PAVMs) are abnormal connections of the pulmonary artery to the pulmonary vein, which bypass the normal pulmonary capillary bed. ${ }^{1}$ This leads to a right-to-left shunt the diameter of the feeding vessel. The normal pulmonary capillary bed measures only 8 to $10 \mathrm{mcm}$ in diameter and serves not only to oxygenate blood but also to filter small thrombi and bacteria from passing through the pulmonary vascular bed. ${ }^{2}$ Approximately $70 \%$ of patients with PAVMs are symptomatic from their right-to-left shunt. Symptoms may be mild due to poor oxygen exchange resulting in dyspnea or hypoxemia, or more severe as a result of paradoxical emboli causing transient ischemic attacks (TIAs), stroke, brain abscess, systemic emboli, or septic emboli. PAVMs can also bleed spontaneously, which can cause massive lifethreatening hemoptysis. ${ }^{3-5}$

Most PAVMs are congenital with the vast majority of patients having hereditary hemorrhagic telangiectasia (HHT), otherwise known as Osler-Weber-Renu syndrome. The literature reports that the incidence of HHT in patients received

March 20, 2017

accepted after revision

May 29, 2017

published online

September 1, 2017
DOI https://doi.org/

10.1055/s-0037-1604096. ISSN 2457-0214.
Copyright $\odot 2017$ by Indian Society of

Vascular and Interventional Radiology
License terms

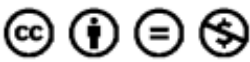


with PAVMs may be as high as $90 \%,{ }^{2,3,6-13}$ with up to $50 \%$ of patients with HHT having PAVMs. The remaining PAVMs can be congenital idiopathic lesions, or acquired such as in the setting of cirrhosis with hepatopulmonary syndrome or after treatment of complex cyanotic cardiac disease. ${ }^{14}$

PAVM embolization, which was first described by Porstmann in $1977,{ }^{15}$ is now the current standard of care for a PAVM with a feeding vessel $\geq 2$ to $3 \mathrm{~mm}^{3,5,6,10,16-19}$ Technical success rate has been reported to be as high as 88 to $100 \%$; however, up to $25 \%$ of technically successful embolizations may require retreatment. ${ }^{17}$ Retreatment has been indicated in the patients who on follow-up imaging have signs of an enlarged PAVM or persistence whether it is from recanalization, growth of a missed accessory vessel, or collateral reperfusion from pulmonary or systemic branches. Reperfusion rates have been reported ranging from 5 to $57 \% .{ }^{17,20}$ Currently, reperfused pulmonary arteriovenous malformations (rPAVMs) are treated regardless of whether or not the patient is symptomatic for fear that he/she is at continued risk for complications from paradoxical embolization. In this study, the authors sought to assess the clinical significance of rPAVMs.

\section{Methods}

\section{Patient Population}

All patients with PAVMs who underwent angiography and embolization between January 1,2006 and December 30, 2007 from a single HHT center were included in this retrospective review. Approval from our institutional review board (Human Investigation Committee Protocol 131001294) was obtained. Patients with diffuse PAVMs, defined by a PAVM involving each subsegmental artery of at least one lobe, were excluded. However, patients with multiple focal PAVMs were included.

Patient charts and imaging studies were reviewed at the time of the embolization and during a follow-up period through December 30, 2013. The following information was recorded: patient demographics, HHT diagnosis and genetic subtype (when available), clinical symptoms both at the time of embolization and during the follow-up period, and imaging findings at the time of embolization and during the follow-up period. The clinical symptoms recorded included hypoxic-related symptoms, anemia, TIA, stroke, septic emboli, hemoptysis, hemothorax, and migraines. Note was taken of any factors that may have contributed to or caused the symptom not related to the PAVM. The clinical symptoms were subsequently graded as mild (hypoxic-related events, anemia, and migraine) or severe (TIA, stroke, septic emboli, hemoptysis, and hemothorax).

\section{Procedure}

Procedures were performed via a right common femoral vein approach. Initial pulmonary artery pressures and bilateral pulmonary artery angiograms were performed. Once the PAVM was identified, the White Lumax Guide Catheter (Cook Medical, Bloomington, Indiana, United States) was introduced. Often, the feeding vessel was selected with the $5 \mathrm{~F}$ inner catheter, and if needed, microcatheters were used. Embolization was performed with appropriately oversized coils.

\section{Imaging Findings}

All angiographic and computed tomographic images were reviewed by one of the authors for imaging performed at the time of initial embolization as well as any further studies performed during the follow-up period. Note was made of the size of the feeding vessel and the location for all PAVMs, whether or not recanalization was present on previously embolized PAVMs, as well as the presence, number, and location of any new significant PAVMs. Additionally, note was made of the pulmonary artery pressure prior to treatment.

\section{Statistical Analysis}

Descriptive statistics were performed to examine patient demographics. A Fischer exact test was performed to compare symptoms in patients with rPAVMs alone versus those with rPAVM and additional new significant PAVMs.

\section{Results}

During the 2-year treatment period from January 1, 2006 and December 30, 2007, there were 101 patients at our institution who underwent PAVM embolization ( - Table 1) with a total of 216 treated for PAVMs. Twenty-seven of these patients were treated for rPAVM for lesions treated either before this time period at our own institution or lesions previously treated at another institution. Twenty-six of these patients were previously embolized with coils, and one had been embolized with a detachable balloon. None of these patients developed a recurrent rPAVM during follow-up period. Three patients who underwent initial coil embolization of a PAVM at our institution developed rPAVM during the follow-up period through December 30, 2013. This resulted in a total of 30 patients with rPAVMs with a total of 36 rPAVMs.

Table 1 Demographics of 101 patients undergoing PAVM embolization from January 1, 2006 to December 30, 2007

\begin{tabular}{|c|c|}
\hline \multicolumn{2}{|l|}{ Age } \\
\hline Mean & 42 y old \\
\hline Range & $11-85$ y old \\
\hline \multicolumn{2}{|l|}{ Sex } \\
\hline Male & 41 \\
\hline Female & 60 \\
\hline \multicolumn{2}{|l|}{ HHT } \\
\hline Yes & 97 \\
\hline No/Negative genetic Testing & 4 \\
\hline \multicolumn{2}{|l|}{ HHT type } \\
\hline Type 1 & 37 \\
\hline Type 2 & 7 \\
\hline VUS ENG mutation & 2 \\
\hline SMAD4 mutation & 1 \\
\hline Negative genetic testing & 3 \\
\hline No genetic testing & 51 \\
\hline
\end{tabular}

Abbreviation: $\mathrm{HHT}$, hereditary hemorrhagic telangiectasia. 
Table 2 Patients with reperfused pulmonary arteriovenous malformations

\begin{tabular}{|l|l|l|}
\hline & Patients & Comment \\
\hline Total patients treated & 101 & \\
\hline rPAVM & 30 & \\
\hline $\begin{array}{l}\text { Reperfused previously embolized PAVM at the time } \\
\text { of entry into the study period }\end{array}$ & 27 & $\begin{array}{l}\text { 26 patients with coil embolized, 1 patient embolized with } \\
\text { detachable balloon. None were again reperfused } \\
\text { during follow-up period. }\end{array}$ \\
\hline rPAVM during follow-up & 3 & All patients were newly coil-embolized \\
\hline Symptomatic with rPAVM & $18(60 \%)$ & \\
\hline Symptomatic attributed to PAVM or rPAVM & $16(53 \%)$ & \\
\hline
\end{tabular}

Abbreviations: PAVM, pulmonary arteriovenous malformation; rPAVM, reperfused pulmonary arteriovenous malformation.

Out of the 30 patients with rPAVM, 18 (60\%) patients were found to be symptomatic at the time of presentation of the rPAVM (-Table 2 ). Two of the symptomatic rPAVM patients were excluded on the basis of respiratory manifestations that were felt to be related to medical comorbidities, not their PAVM (-Tables 3, 4).

Fourteen of the remaining 16 symptomatic patients with rPAVMs had at least one other significant PAVM at the time of diagnosis of reperfusion. Only two symptomatic patients had only an rPAVM. Both these patients presented with mild symptoms: one patient had respiratory symp- toms and migraines whereas the other only had respiratory symptoms.

There were 12 asymptomatic patients with rPAVM. Of these, 10 presented with only rPAVM, whereas 2 had additionally a new significant nonembolized PAVM. Only two patients with rPAVM presented with severe symptoms: one presenting with stroke and the other with TIA. Both these patients had another significant PAVM in addition to rPAVM (-Table 5).

Angiographic examination and possible embolization were performed on all rPAVMs regardless of symptomatology.

Table 3 Patients excluded for symptoms felt to be due to comorbidities not rPAVM

\begin{tabular}{|l|l|l|l|l|l|}
\hline & rPAVM & Symptomatic & $\begin{array}{l}\text { Hypoxic-related } \\
\text { symptoms }\end{array}$ & $\begin{array}{l}\text { Other symptoms } \\
\text { (migraine, anemia, } \\
\text { hemothorax, hemoptysis, } \\
\text { migraine, TIA, stroke, } \\
\text { septic emboli) }\end{array}$ & Cause for symptom not PAVM related \\
\hline Patient 1 & Yes & Yes & Yes & No & OSA, smoker, weight gain \\
\hline Patient 2 & Yes & Yes & Yes & No & OSA \\
\hline
\end{tabular}

Abbreviations: OSA, obstructive sleep apnea; PAVM, pulmonary arteriovenous malformation; rPAVM, reperfused pulmonary arteriovenous malformation; TIA, transient ischemic attack.

Table 4 Symptoms in patients with rPAVMs

\begin{tabular}{|l|l|l|l|}
\hline & $\begin{array}{l}\text { No. of } \\
\text { patients }\end{array}$ & $\begin{array}{l}\text { No. of patients } \\
\text { with just rPAVM }\end{array}$ & $\begin{array}{l}\text { No. of patients with rPAVM and } \\
\text { nonembolized significant PAVM }\end{array}$ \\
\hline No symptoms & 12 & $10^{*}$ & $2^{*}$ \\
\hline Any symptoms & 16 & $2^{*}$ & $14^{*}$ \\
\hline Mild symptoms only-total & 13 & 2 & 11 \\
\hline Respiratory & 11 & 1 & 10 \\
\hline Migraines & 7 & 2 & 5 \\
\hline Severe symptoms-total & 2 & 0 & 3 \\
\hline Hemoptysis & 1 & 0 & 1 \\
\hline Stroke or TIA & 2 & 0 & 2 \\
\hline Brain or systemic abscess & 0 & 0 & 0 \\
\hline
\end{tabular}

Abbreviations: PAVM, pulmonary arteriovenous malformation; rPAVM, reperfused pulmonary arteriovenous malformation; TIA, transient ischemic attack. ${ }^{*} p=0.0004$ on Fischer exact test. 
Table 5 Etiology of PAVM reperfusion on 27 patients included in this study

\begin{tabular}{|l|l|}
\hline Cause of reperfusion & No. of patients \\
\hline Recanalization & 16 \\
\hline Missed accessory vessel & 3 \\
\hline $\begin{array}{l}\text { Recanalization and missed } \\
\text { accessory vessel }\end{array}$ & 3 \\
\hline $\begin{array}{l}\text { Collateral perfusion from a pulmonary } \\
\text { artery branch }\end{array}$ & 3 \\
\hline $\begin{array}{l}\text { Collateral perfusion from a pulmonary } \\
\text { artery branch and recanalization }\end{array}$ & 1 \\
\hline $\begin{array}{l}\text { Deflated gold valve balloon and coil } \\
\text { recanalization }\end{array}$ & 1 \\
\hline $\begin{array}{l}\text { Collateral perfusion from a systemic } \\
\text { or bronchial branch }\end{array}$ & $1^{*}$ \\
\hline
\end{tabular}

Abbreviation: PAVM, pulmonary arteriovenous malformation.

*This patient presented with recurrent hemoptysis of uncertain etiology; either collateral reperfusion from a hypertrophied bronchial artery or coil erosion into the right upper lobe bronchus.

Two patients without symptoms and five patients with mild symptoms underwent angiographic evaluation but not embolization. These rPAVMs were felt to be too small to cause patients symptoms or were technically challenging. All these patients underwent subsequent imaging follow-up performed at or reviewed by our institution with the exception of one patient whose follow-up imaging was performed elsewhere.

The etiologies of the rPAVM included in our study included isolated recanalization of a previously coil embolized PAVM (-Fig. 1) in 16 patients, isolated missed accessory vessel in 3 patients, 3 patients with both coil recanalization and a missed

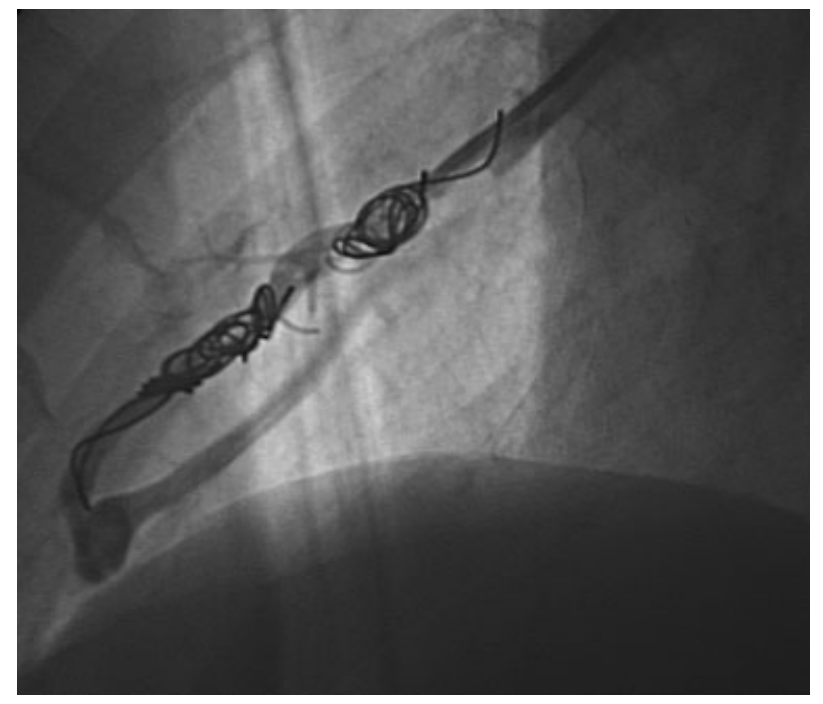

Fig. 1 Angiogram with selective catheterization demonstrates recanalization of a right lower lobe PAVM previously embolized with coils. The patient initially presented 4 years prior with a brain abscess thought to be due to septic emboli from the PAVM. At the time of this follow-up angiogram demonstrating recanalization, the patient was asymptomatic and found to have no additional newly enlarged PAVMs. accessory vessel, 3 patients with isolated collateral perfusion from a pulmonary artery branch, 1 patient with both coil recanalization and collateral reperfusion from a pulmonary artery branch, and 1 patient reperfusion due to a deflated gold valve balloon that was placed in 1994 in addition to coil recanalization (-Table $\mathbf{5}$ ). One patient presented with recurrent hemoptysis and previous bronchial artery embolization. Imaging showed a hypertrophic bronchial artery measuring $2 \mathrm{~mm}$ suggesting this to be the possible etiology; however, upon bronchoscopy, a coil was seen projecting into the bronchial lumen. Though this patient clearly has a complication related to PAVM embolization, it is unclear whether the hemoptysis was due to bronchial/systemic collateralization versus coil erosion.

Symptomatic patients with rPAVM were more likely to have additional significant nonembolized PAVM than asymptomatic patients with rPAVM, with a significant $p$ value of 0.0003 .

\section{Discussion}

PAVMs are known to put patients at risk of serious and even life-threatening complications due to paradoxical embolization and hemorrhage, especially if left untreated. ${ }^{12}$ This has led to a recommendation that PAVMs with feeding vessels $\geq 3 \mathrm{~mm}$ should be embolized to prevent migration of larger clots, although more recent literature has suggested that paradoxical embolization can occur with even smaller feeding vessels. It may not be possible to determine the patient's risk directly related to feeding vessel size. ${ }^{21-24}$

Reperfusion of a previously embolized PAVM has been shown to occur from 5 to $57 \%$ of patients, with a recent study by Woodward et al reporting persistence in $25 \%{ }^{12,17,20}$ Our study showed reperfusion in $16.7 \%$ of the PAVMs treated. Reperfusion can occur through recanalization of the embolized vessel (most commonly described with coils), a missed accessory vessel, collateral reperfusion from adjacent pulmonary arteries distal to the site of embolization, or collateral reperfusion from bronchial or other systemic vessels distal to the site of embolization. ${ }^{6,10,17,18,25}$ Patients with reperfusion typically undergo retreatment of the rPAVM as it is thought they have increased risk of paradoxical embolization due to incomplete closure of the shunt and a continued risk of hemorrhage.

A previous study by Woodward et al looked at 23 patients with PAVM who underwent 71 procedures treating 162 PAVMs, 57 of which had been previously treated. They found that none of the patients with persistence of a PAVM had brain abscess or stroke during the time of persistence. ${ }^{17}$

Our study specifically examined the clinical symptoms of patients presenting with rPAVMs, in addition to documenting any additional new significant PAVMs. To our knowledge, this is the first study correlating patient symptoms and rPAVMs with additional new significant PAVMs.

The authors found that patients with clinical symptoms were significantly more likely to have a nonembolized now significant-sized PAVM (believed to be enlargement of previously tiny lesions), in addition to the rPAVM. A prior study has shown that growth or enlargement of PAVMs previously too small to embolize occurs in up to $18 \%$ of patients. ${ }^{6}$ of 
note, none of the patients with severe symptoms in this study had an rPAVM alone. This leads the authors to believe that it may not be the reperfusion of the PAVM, which caused patient symptoms but rather the newly significant-sized other PAVMs related to the underlying pathology and HHT.

It should be noted that all the coil-embolized rPAVMs during the time of this study were densely packed. This may also account for a reduced risk of macroscopic paradoxical embolization through such lesions given the small channels available through the coil matrix. Indeed, one patient embolized with stainless steel coils in the early 1990s has since developed a small stroke after the end of this study's period from a solitary significant-sized rPAVM, with only very tiny other PAVMs present. The coils in this lesion were indeed found to be loosely packed.

There were several limitations to our study, which are in large part due to the retrospective review design and limited patient sample size. Additionally, patient charts were reviewed for clinical symptoms. This is prone to recall bias as the patient had to report the subjective symptoms such a migraines and dyspnea. Finally, the annual occurrence of a symptomatic paradoxical embolus appears to be fairly low. Though our follow-up spanned 7 to 8 years, this may not be enough to assess the lifelong risk to patients with rPAVM and so could have underestimated their significance.

\section{Conclusion}

The majority of symptomatic patients with rPAVM had additional newly enlarged PAVMs that required embolization. None of the symptomatic patients with rPAVM alone had severe manifestations, suggesting that rPAVM plays a small role in patients with recurrent severe symptoms and may not need to be reembolized. However, given the nature of HHT and low annual risk from PAVM, close follow-up remains important for to evaluate for newly enlarging PAVMs as well as rPAVM.

\section{Conflict of Interest \\ None.}

\section{Acknowledgment}

The authors would like to thank Dr. Robert White Jr. for his support, contributions, and mentorship with this project.

\section{References}

1 Bosher LH Jr, Blake DA, Byrd BR. An analysis of the pathologic anatomy of pulmonary arteriovenous aneurysms with particular reference to the applicability of local excision. Surgery 1959;45 (01):91-104

2 Cartin-Ceba R, Swanson KL, Krowka MJ. Pulmonary arteriovenous malformations. Chest 2013;144(03):1033-1044

3 Trerotola SO, Pyeritz RE. PAVM embolization: an update. AJR Am J Roentgenol 2010;195(04):837-845

4 Shovlin CL, Letarte M. Hereditary haemorrhagic telangiectasia and pulmonary arteriovenous malformations: issues in clinical management and review of pathogenic mechanisms. Thorax 1999;54(08):714-729
5 White RI Jr, Pollak JS, Wirth JA. Pulmonary arteriovenous malformations: diagnosis and transcatheter embolotherapy. J Vasc Interv Radiol 1996;7(06):787-804

6 Pollak JS, Saluja S, Thabet A, Henderson KJ, Denbow N, White RI Jr. Clinical and anatomic outcomes after embolotherapy of pulmonary arteriovenous malformations. J Vasc Interv Radiol 2006; 17(01):35-44, quiz 45

7 Gossage JR, Kanj G. Pulmonary arteriovenous malformations. A state of the art review. Am J Respir Crit Care Med 1998;158(02):643-661

8 Gupta P, Mordin C, Curtis J, Hughes JM, Shovlin CL, Jackson JE. Pulmonary arteriovenous malformations: effect of embolization on right-to-left shunt, hypoxemia, and exercise tolerance in 66 patients. AJR Am J Roentgenol 2002;179(02):347-355

9 Haitjema TJ, Overtoom TT, Westermann CJ, Lammers JW. Embolisation of pulmonary arteriovenous malformations: results and follow up in 32 patients. Thorax 1995;50(07):719-723

10 Mager JJ, Overtoom TT, Blauw H, Lammers JW, Westermann CJ. Embolotherapy of pulmonary arteriovenous malformations: long-term results in 112 patients. J Vasc Interv Radiol 2004; 15(05):451-456

11 Puskas JD, Allen MS, Moncure AC, et al. Pulmonary arteriovenous malformations: therapeutic options. Ann Thorac Surg 1993; 56(02):253-257, discussion 257-258

12 Swanson KL, Prakash UB, Stanson AW. Pulmonary arteriovenous fistulas: Mayo Clinic experience, 1982-1997. Mayo Clin Proc 1999;74(07):671-680

13 White RI Jr, Lynch-Nyhan A, Terry P, et al. Pulmonary arteriovenous malformations: techniques and long-term outcome of embolotherapy. Radiology 1988;169(03):663-669

14 Vettukattil JJ. Pathogenesis of pulmonary arteriovenous malformations: role of hepatopulmonary interactions. Heart 2002; 88(06):561-563

15 Porstmann W. Therapeutic Embolization of Arteriovenous Pulmonary Fistula by Catheter Technique. Berlin, Germany: Springer; 1977

16 White RI Jr. Pulmonary arteriovenous malformations: how do we diagnose them and why is it important to do so? Radiology 1992; 182(03):633-635

17 Woodward CS, Pyeritz RE, Chittams JL, Trerotola SO. Treated pulmonary arteriovenous malformations: patterns of persistence and associated retreatment success. Radiology 2013;269(03):919-926

18 Lee DW, White RI Jr, Egglin TK, et al. Embolotherapy of large pulmonary arteriovenous malformations: long-term results. Ann Thorac Surg 1997;64(04):930-939, discussion 939-940

19 Milic A, Chan RP, Cohen JH, Faughnan ME. Reperfusion of pulmonary arteriovenous malformations after embolotherapy. J Vasc Interv Radiol 2005;16(12):1675-1683

20 Sagara K, Miyazono N, Inoue H, Ueno K, Nishida H, Nakajo M. Recanalization after coil embolotherapy of pulmonary arteriovenous malformations: study of long-term outcome and mechanism for recanalization. AJR Am J Roentgenol 1998;170(03):727-730

21 Trerotola SO, Pyeritz RE, Bernhardt BA. Outpatient single-session pulmonary arteriovenous malformation embolization. J Vasc Interv Radiol 2009;20(10):1287-1291

22 Todo K, Moriwaki H, Higashi M, Kimura K, Naritomi H. A small pulmonary arteriovenous malformation as a cause of recurrent brain embolism. AJNR Am J Neuroradiol 2004;25(03):428-430

23 Shovlin CL, Jackson JE, Bamford KB, et al. Primary determinants of ischaemic stroke/brain abscess risks are independent of severity of pulmonary arteriovenous malformations in hereditary haemorrhagic telangiectasia. Thorax 2008;63(03):259-266

24 Andersen PE, Kjeldsen AD. Embolization of pulmonary AVMs of feeding arteries less than $3 \mathrm{~mm}$ : reports of two cases and an 8-year follow-up without embolization. Acta Radiol Short Rep 2012;1(02):arsr.2012.120001

25 Saluja S, Sitko I, Lee DW, Pollak J, White RI Jr. Embolotherapy of pulmonary arteriovenous malformations with detachable balloons: long-term durability and efficacy. J Vasc Interv Radiol 1999;10(07):883-889 